\title{
New titles to brighten your year
}

\section{Compiled by Helen Nield}

To borrow any of these titles please email library@bda.org or call 0207563 4545. Although members are responsible for return postage costs, books are sent out to them free of charge. They may be kept for at least four weeks and can be renewed if not requested by others. Members can now loan up to ten items at any one time.

\section{IMPLANT THERAPY - CLINICAL APPROACHES AND EVIDENCE OF SUCCESS (2ND EDITION)}

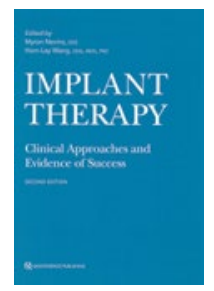

Myron Nevins and Hom-Lay Wang (Editors)

2019; Quintessence Publishing; 528 pp; hardback

ISBN: 9780867157987

'Can we or should we preserve the remaining natural dentition, or do implants offer a more predictable prognosis? This text addresses the challenge of decision making with specific solutions for each area of the dentition.'

The first edition of this book was published way back in 1998. This now vastly expanded, completely updated and weighty textbook $(2.75 \mathrm{~kg})$ is really a completely different book to the earlier version. With an interesting first chapter on making the clinical decision either to 'save the tooth or place an implant' it covers the full range of implant therapy from 'diagnosis and treatment planning through various treatment modalities' and concluding with the 'maintenance of the result' being very aware of the many complications in implant treatment and the challenge of peri-implantitis. It is packed full of glossy images, very clear and easily read text and a comprehensive index.

\section{THE ORTHO-PERIO PATIENT - CLINICAL EVIDENCE \& THERAPEUTIC GUIDELINES}

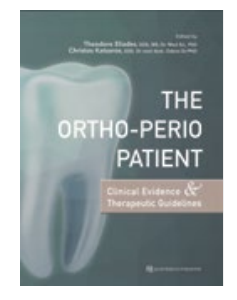

Theodore Eliades and Christos Katsaros (Editors) 2019; Quintessence Publishing; 216 pp; hardback ISBN: 9780867156799 'The evidence provided in this book and the case series portraying the adjunct role of each specialty in the treatment planning of patients with periodontal or orthodontic needs furnish important theoretical and clinical information as well as practical guidelines to improve the treatment outcome of therapeutic protocols involving ortho-perio interventions.'

There are very few books that cover both these disciplines as they impact on each other. The only other titles in the library collection are Heasman's The periodontium and orthodontics in health and disease from 1996 and a small paperback from Scholar's press in 2013, A dynamic relationship between orthodontics and periodontics. This current textbook is split into three sections covering the fundamentals of oral physiology, periodontal considerations for the orthodontic patient and orthodontic considerations for the periodontic patient. Edited by a Swiss duo there are 28 contributors listed and it has obviously been a global collaboration. Intended to be used not as a reference book it also includes 'substantiated guidelines' and treatment approaches that will help in the production of treatment plans. This book can also be read as part of the library's ebook collection - www.bda.org/ebooks.

\section{DIGITAL WORKFLOW IN RECONSTRUCTIVE DENTISTRY}

\section{Wael Att, Siegbert Witkowski and Jörg Strub}

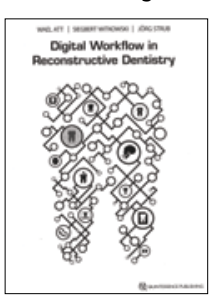

2019; Quintessence Publishing; 327 pp; hardback ISBN: 9781786980250

'The digital workflow in reconstructive dentistry has been described by Att and Gerard ...

as comprised of three main components; starting with data acquisition, followed by data processing and planning, and finally with the execution of treatment or fabrication.'

A production of the academic team at the Department of Prosthodontics, University Hospital of Freiburg this book aims to point a way through the plethora of digital innovations and show the advantages and disadvantages of many of the new technologies in the context of a digital workflow. Its aim is to 'build a fundamental understanding of the general principles, science, and clinics of digital dental medicine'. Chapters cover various scanning technologies, radiographic imaging, virtual registration, mounting, and articulation, digital assessment tools and data manipulation, computer-guided implant planning and surgery and $\mathrm{CAD} /$ CAM. The penultimate chapter consists of three digital workflow cases and the book finishes with a look at the future.

\section{NEXT-GENERATION BIOMATERIALS FOR} BONE \& PERIODONTAL REGENERATION

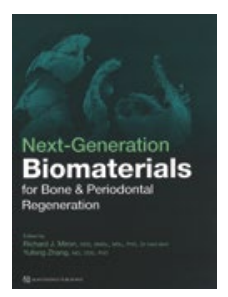

Richard J. Miron and Yufeng Zhang 2019; Quintessence Publishing; 370 pp; hardback ISBN: 9780867157963

'The use of bone grafting materials in implant dentistry, periodontology, and oral surgery has become so widespread over the past two decades that new products are rapidly being brought to market year after year, each with various claims in their regenerative potential.'

This book has been designed to address the gap in knowledge for dental practitioners faced with a plethora of new biomaterials, regenerative modalities and protocols for patient care. The first ten chapters look at the 'biologic background and applications of bone grafting materials' in dentistry, chapter 11 covers guided tissue and bone regeneration, chapter 12 explores the more natural approach of platelet-rich fibrin and chapters 13-22 look in depth at the increasing use of growth factors for bone regeneration. The authors consider the final chapter, 23 , to be perhaps the most important one as it covers selection criteria and the process of decision making and is designed to help clinicians select the appropriate biomaterials for each 'specific regenerative protocol. This book can also be read as part of the library's ebook collection www.bda.org/ebooks. 